torily hented ; but care should be taken not to burn too deeply with these fine-pointed instruments, as hacmorrhage may be produced. In diffuse hypertrophy I resort to tapping all over the affected part with a fine burner, the part afterwards presenting a number of small white eschars. The soft palate may be conveniently pushed out of the way with a laryngeal mirror, etc., when its movements impede the operation, or when the higher parts of the pharynx are to be cauterised. Certainly nothing, in my opinion, is so effectual and attended with such gratifying results as the galvano-cautery. Schech sometimes excises the lateral bands with a knife when they are hard and thickened.

There is generally a certain amount of reaction after these operations, and the more so the more extensive the operation. It is always well, therefore, to enjoin rest in bed the same day, and, if the operation has been fairly extensive, to give one or two doses of morphine afterwards. Subsequent pain or inflammation may be relieved by sucking ice and the application of 25 to 30 per cent. of menthol in raseline oil.

Uvulatomy may be practised when the urula is hypertrophied and elongated, and giving rise to a constant but ineffectual swallowing, tickling and irritation in the throat; and also in those extremely rare cases where, owing to its being sucked into the larynx during sleep, attacks of suffocation are induced. The end of the uvula is seized with a pair of forceps, put slightly on the stretch, and a small but sufficient portion removed with scissors or bistoury. Sometimes there is considerable subsequent angina, which may be combated by sucking ice and the application of a pigment of menthol. This operation, however, is often abused, and in doubtful cases of throat irritation and hacking cough, other possible causes of these symptoms should be first excluded.

In the employment of cocaine for the removal of pain in pharyngeal operations, it is best to use the drug in a fairly concentrated solution-for example, 20 per cent. The brush slould not be overladen with it, as an unnecessary amount increases the risk of producing some of the disagreeable symptoms which cocaine, when concentrated, may produce. Thus I have frequently seen attacks of retching, vomiting, faintness, with copious sweating, and in a few cases syncope, and lave recourse to strophanthus, with spirits of ether or sal rolatile, when I see symptoms of faintness coming on. It is better rather to make two or three applications of a very small amount of the solution, and to rub it well into the surface to be operated on, as so doing materially aids the substance in producing anæesthesia. The surface application of a less than 15 per cent. solution of cocaine is not very effectual for operative procedures. Merck's hydrochlorate of cocaine is the most reliable preparation I have used.

In treating catarrh of the pharynx it is important to secure the integrity of the nose and naso-pharyngeal space, so as to ensure respiration through the normal channel and prevent the external air from coming into direct contact with the throat. Excessive smoking, the taking of strong spirituous liquors and highly-seasoned and irritating food, and the overstraining of the voice, especiully in the open air, should be avoided. A good hygiene also should be enjoined, especially when ear complications are present. Daily sponging or bathing with tepid water in winter and cold in summer (salt water preferably), followed by rubbing with coarse towels, materially assists in the treatment by hardening the skin and rendering the pharynx less liable to attacks of inflammation. The administration of saline purgatives will be found useful in plethoric individuals. In short, all exciting causes should, if possible, be removed, while any constitutional dyscrasia or any diseased system will call for special trentment.

Bequests $\triangle N D$ Donations-The trustees of the late Mr. George Sturge have given $£ 200$ (additional) to the Charing Cross Hospital, \&:00 (additional) to University College Hospital, and $£ 100$ to the Metropolitan Convalescent Institution.-The Corporation of the City of London have voted 100 guineas (additional) to the Royal Hospital for Women and Children.-The Mercers' Company have given 100 guineas (second time) to the Convalescent Home at Felixstowe.-The Grocers' Company have given $f 100$ (additional) to the Royal Free Hospital.-The Norfolk and Norwich Eye Infirmary has received $\$ 100$ under the will of Lord Ramsey. Chloral Poisoning.-Mr. Frederick Thomas Welham, a veterinary surgeon, aged 41, practising at Brentwood, has met his death from an overdose of chloral, taken, it is supposed, for the purpose of inducing sleep. Becoming conscious of what he had done, he asked for water and oil, the administration of which caused bim to romit, but death ensued in a few minutes.

\section{REMARKS ON INTUBATION OF THE LARYNX.}

Read in the Section of Diseases of Children at the Annual Meeting of the British Medical Association, held in Glasgow, August, $188 s$.

By F. E. WAXHAM, M.D., Professor of Otology, Rhinology, and Laryngology in the College of Physicians
aud Surgeons of Chicago.

Nor long since, I received an invitation from your Secretary inviting me to be present at this meeting, and to take part in the discussion on diphtheria. I wish to say that I fully appreciate the high honour implied by the invitation.

As the time for discussion is necessarily so limited, I hope I may be pardoned if I simply allude to the surgical treatment of the disease.

When during the course of an attack of diphtheria the larynx becomes involved, when the loud stridor of croup is heard, when the roice becomes lost and the dyspnoea urgent, when it becomes evident that death must occur from suffocation unless relief is promptly given, then it becomes an important question to decide as to whether we shall recommend tubage of the laryn $x$ or tracheotomy.

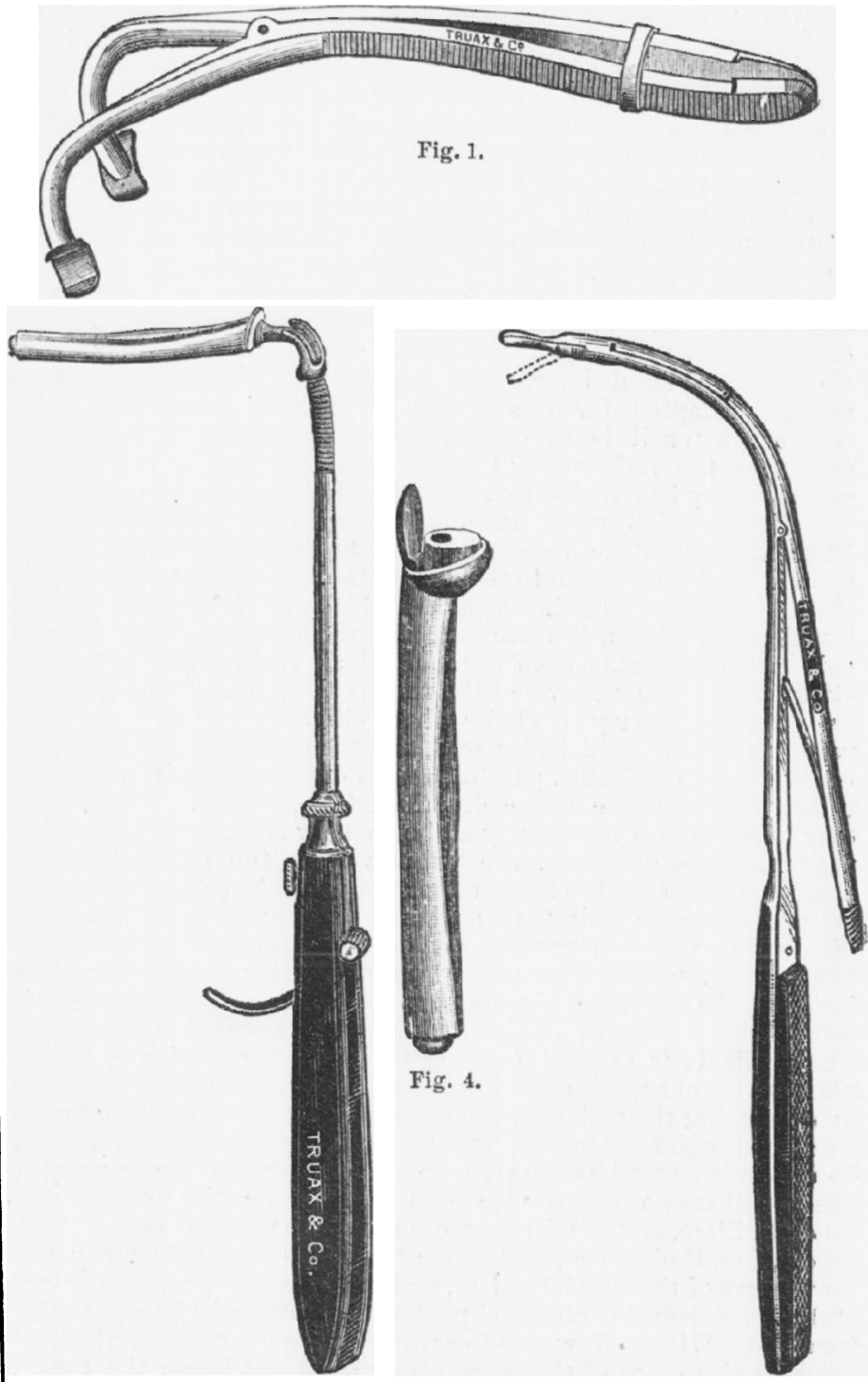

Fig. 2.

Fig. 3.

Intubation of the larynx, for which we owe a debt of gratitude to Dr. O'Dwyer, of New York, is a new operation now in its infancy, and only recently has the most important objection to the operation been overcome, the difficulty of swallowing.

The instruments consist of a gag (Fig. 1), an introducer(Fig. 2), an extractor (Fig. 3), and five tubes of different sizes (Fig. 4): 
The physician who wishes to become expert in performing this operation, should first thoroughly familiarise himself with the instruments. One should handle the instruments frequently, and practise working the sprirg of the introducer, which, by the way, should be operated by the thumb, and not by the forefinger. The extractor should be held in the same manner. It will be a help if one practises introducing the tube into the closed hand of another, detaching the tube, and pressing it down out of sight. As the extraction of the tube is even more difficult than its introduction, it is important also to practise extracting the tube from the closed hand, and to become accustomed to the feeling of the head of the tube, and to appreciate the form of the opening in whatever position it may be placed. The instrument should be held lightly, and the operation should be performed with the utmost gentleness. I have no sympathy for those who declare the instruments are not strong enough, and who break their gags, their introducers or extractors. The same quickness and gentleness that is employed in passing a catheter should be exercised in passing i tube into the larynx. No force should be used, no anæsthetic is required, and the operation should not require longer than from five to ten seconds. It is not only important to become perfectly familiar with the instruments and the details of the operation, but, if possible, with the anatomy of the larynx by practical work upon the cadaver.

In performing the operation, the physician should first select a tube suitable to the age of the patient, the smallest being suitable for a child under 2 years;

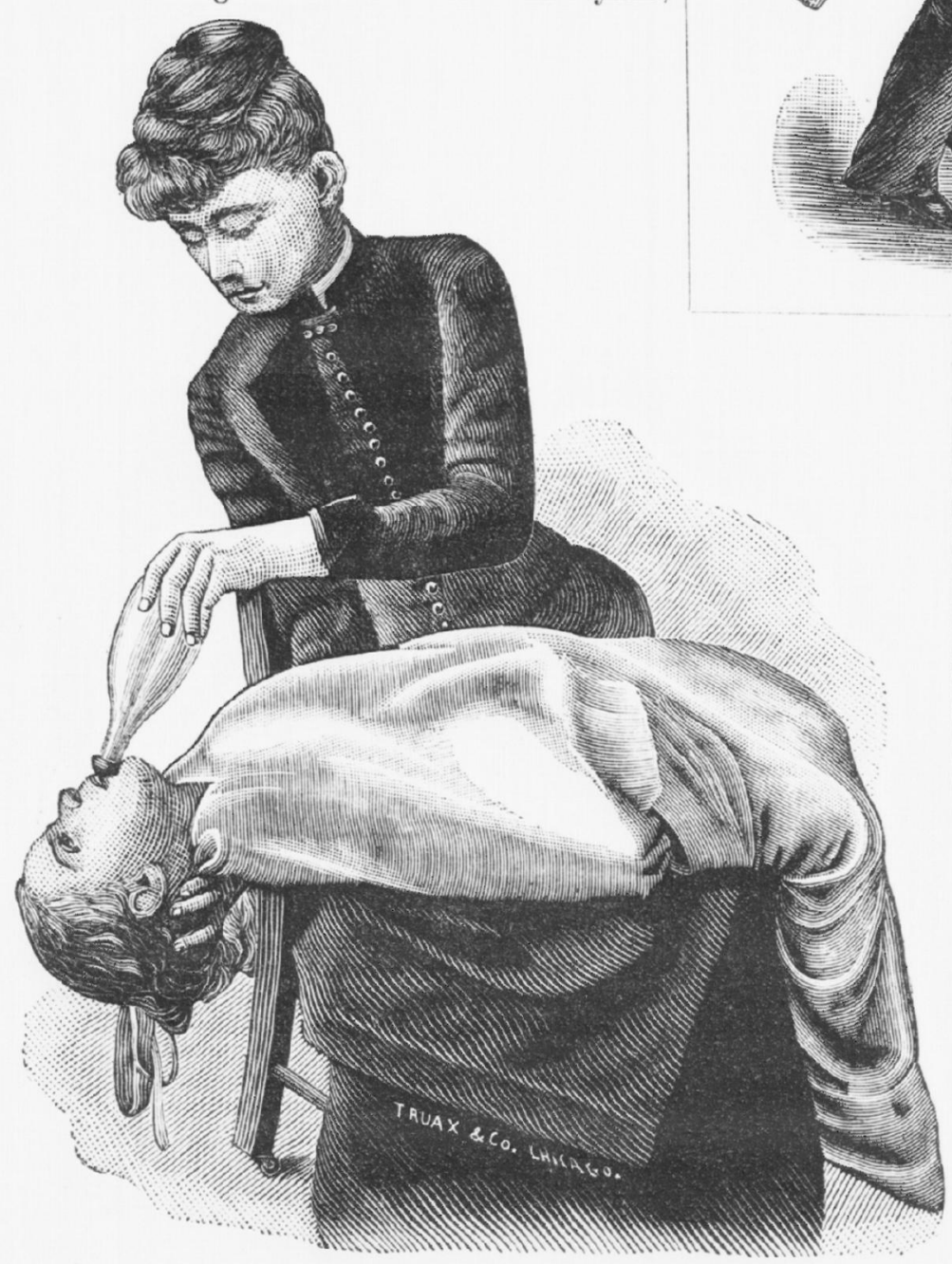

Fig. 5.

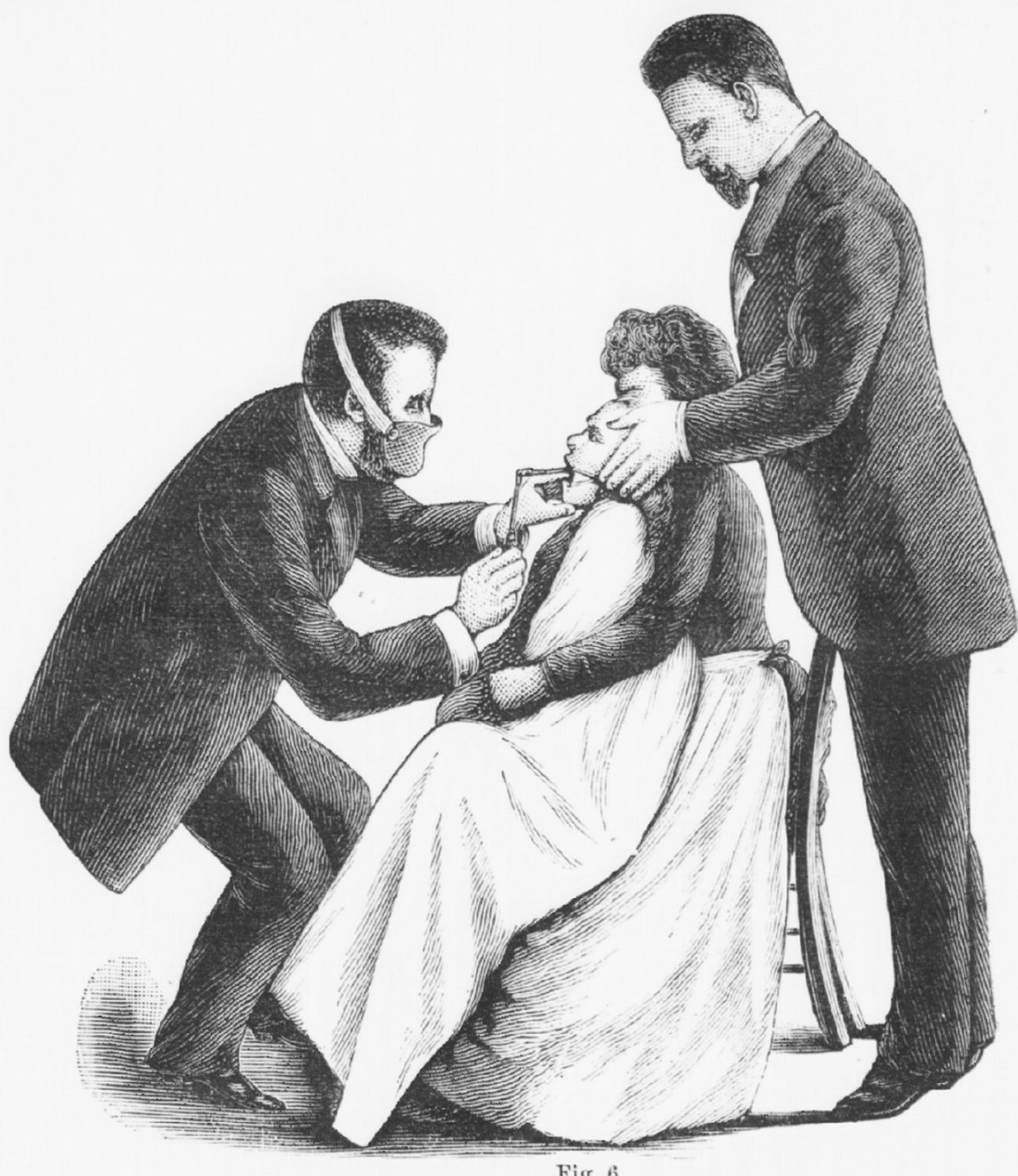

the next in size is appropriate for one between 2 and 4 ; the next for one from 4 to 6 ; the next from 6 to 8 ; the next from 8 to 10 ; and if the extra tube is included in the set, it is appropriate for a child from 10 to 14 years. A suitable tube, however, may be selected by reference to the scale which accompanies each set.

The tube should be threaded with braided silk or linen thread, making a loop about sixteen inches in length. The obturator should then be screwed upon the introductr, and the tube attached (Fig. 2). The instrument is then ready for use and should be placed upon a table within easy reach. The patient, properly wrapped, should be held upright in the lap of the nurse closely against the left chest, with the head resting on the shoulder (Fig. 7 ). The nurse should sit upright in a straight-backed chair, and the patient should be held firmly and not permitted to slide down. The forearms of the child should be crossed in front, and the nurse should grasp the wrists. An assistant, standing behind, should hold the head securely and slightly backwards. The gag should be introduced in the left angle of the mouth, well back between the teeth, and widely opened. The operator should then quickly seize the introducing instrument with the tube attached, hook the loop of silk over tle little finger of the left hand, and introduce the index finger of the same hand, closely followed by the tube (Fig. 6). He may simply hook the epiglottis forward with the index finger (Fig. 9) and guide the end of the tube gently over it, when, by making an abrupt turn, he will pass the tube into the larynx if he has been careful to keep in the median line; or, he may pass the index finger over the epiglottis and upon the arytenoid cartilages, and guide the end of the tube into the larynx. In either case the end of the tube should pass under the tip of the finger, not over it or by the side of it, but directly under it. The moment the end of the tube is passed into the larynx, it should be detached from the introducer by pressing forward on the slide, and, as the instrument is removed, the tube should be pressed 
down into position by the finger, which should still remain within the pharynx. No thought should be given to the handle of the introducing instrument, but the mind should be concentrated upon the end of the tube. This should describe a gentle curve until it has passed over the epiglottis, and then it should remain stationary for an instant while the handle is quickly elevated, so that the tube may go down at a right angle.

-That it has entered the larynx will be indicated by violent coughing, and by easy respiration. If it has passed into the cesophagus no relief is given, ther $\theta$ is no violent coughing, and there is gradual shortening of the loop as the tube gravitates

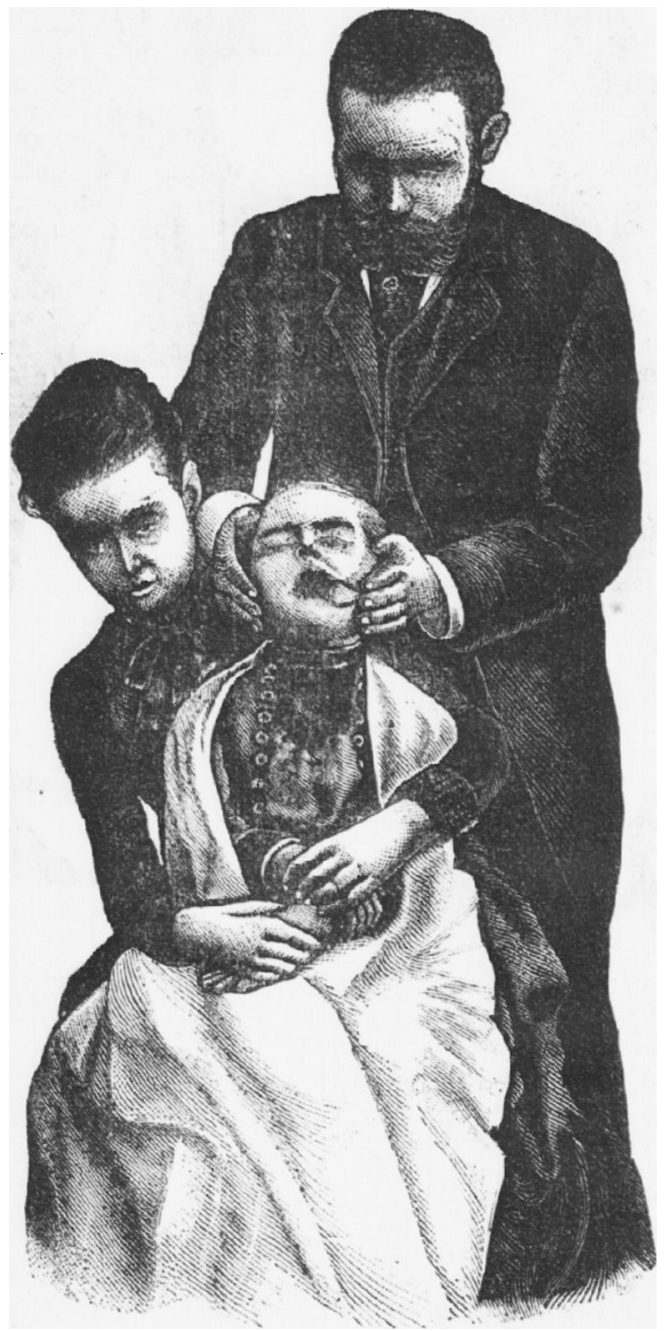

Fig. 7.

towards the stomach. If quite certain that it has entered the larynx the gag should be removed, and the loop should be placed backward over the ear. The operator should wnit a few minutes to make sure the tube is in position, and to allow the cough to expel the ropy mucus and softened membrane. He should then

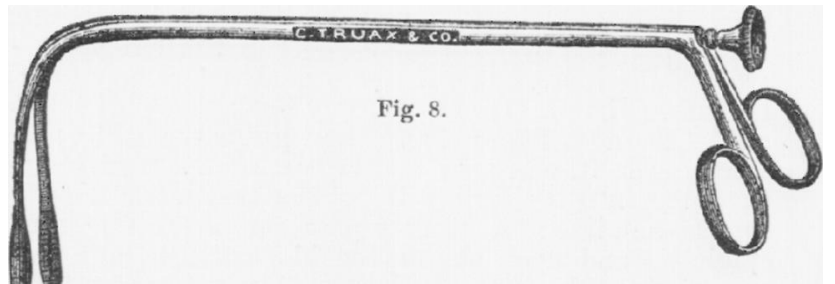

cut the loop near the mouth, replace the gag, and introduce the index finger of the left hand until it reaches the head of the tube ; by pulling on one end of the loop it is quickly removed, leaving the tube within the larynx.
In introducing the tube, if false membrane is crowded down ahead of it which cannot be expelled by coughing, then the tube should be remored at once. If it cannot then be expelled, the trachea forceps which I have had constructed for this purpose (Fig. 8) should be introduced and the membrane removed. If this is not successfully accomplished, and the patient seems about to suffocate, tracheotomy should at once be performed.

In extracting the tube the patient should be placed in the same position as when it was introduced. The gag should be placed as before, and the index finger of the left hand introduced until it reaches the head of the tube. The extractor in the right hand

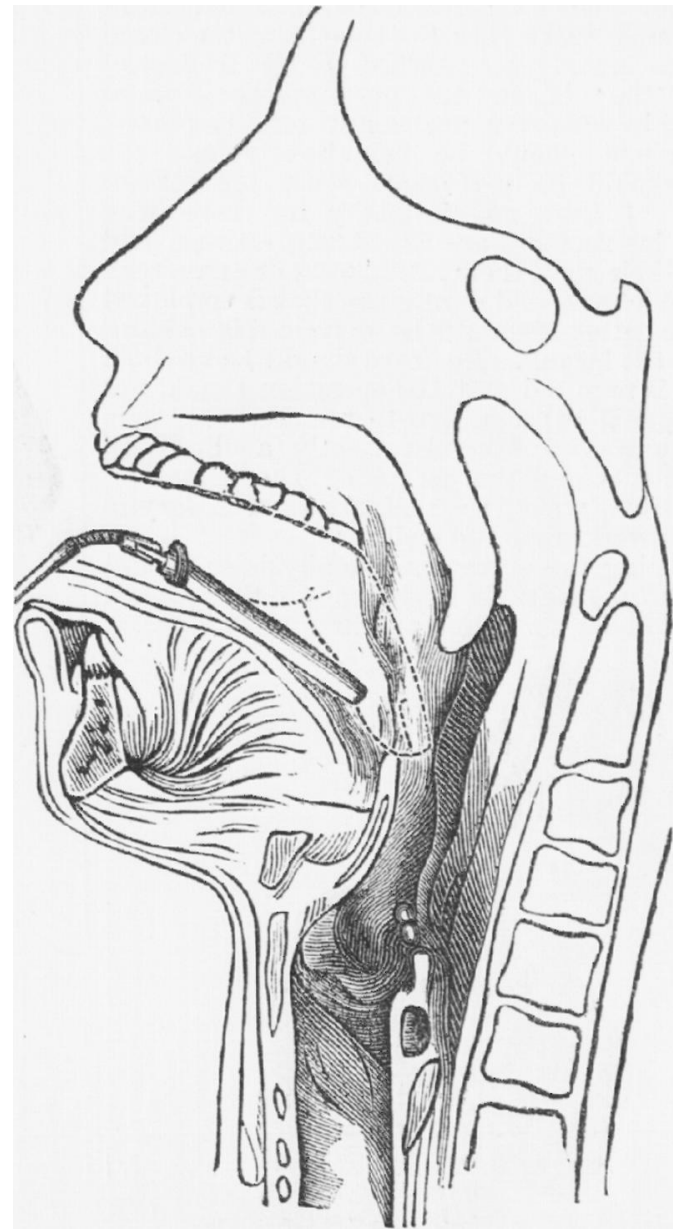

Fig. 9.

should quickly follow the finger, the point of which should be guided into the tube (Fig. 10). By pressing on the lever above the handle the jaws of the instrument are separated, thus holding the tube securely while it is removed. If the tube cannot be removed after a few gentle and careful attempts, then an anæsthetic should be given. In performing the operation a rubber finger cot with the end cut off should be placed on the index finger, to prevent injury from the child's teeth provided the gag should slip.

As an additional precaution, a pad of antiseptic gauze should be placed over the mouth and nostrils of the operator, and secured by a rubber tape passed round the head.

The operation presents many advantages for our consideration. The operation may be performed by the expert quickly, almost instantly. There is no shock, no hæmorrhage, and the relief is as prompt and complete as after tracheotomy. The greatest advantage is the fact that we can always gain the consent of parents, and we will thus save many lives where tracheotomy would not be permitted. The question has been asked, "Should we perform tracheotomy before the occurrence of dyspncea?" I think ve are not justified in resorting to any surgical measure, either to tracheotomy or intubation, until urgent dyspnœe has taken place, and until it is evident that it is the only resource.

As I have hefore stated, all the objections to intubation have 
been overcome, for, by the use of the artificial epiglottis, ${ }^{1}$ it is now posesible for patients, if held in the position shorvn in Fig. 5 , to take an abundance of food, both liquid and solid. For asthetic reasons, therefore, we should recommend intubation. It remains to be shown whether the results compare favourably with those of tracheotomy. Our estimate of tracheotomy will depend in a large measure upon the success it has attained. If one has saved 30,40 , or 50 per cent. of his cases by the operation, he will be reluctant to accept of anything new; but those who have met with poor results or invariable failure will gladly accept an operation that promises so much as intubation. I have now performed intubation 160 times, with 44 recoveries, or 28 per cent. I have collected the reports of 1,072 operutions performed in various parts of the United States, with 287 recoveries, or 27 per cent. It

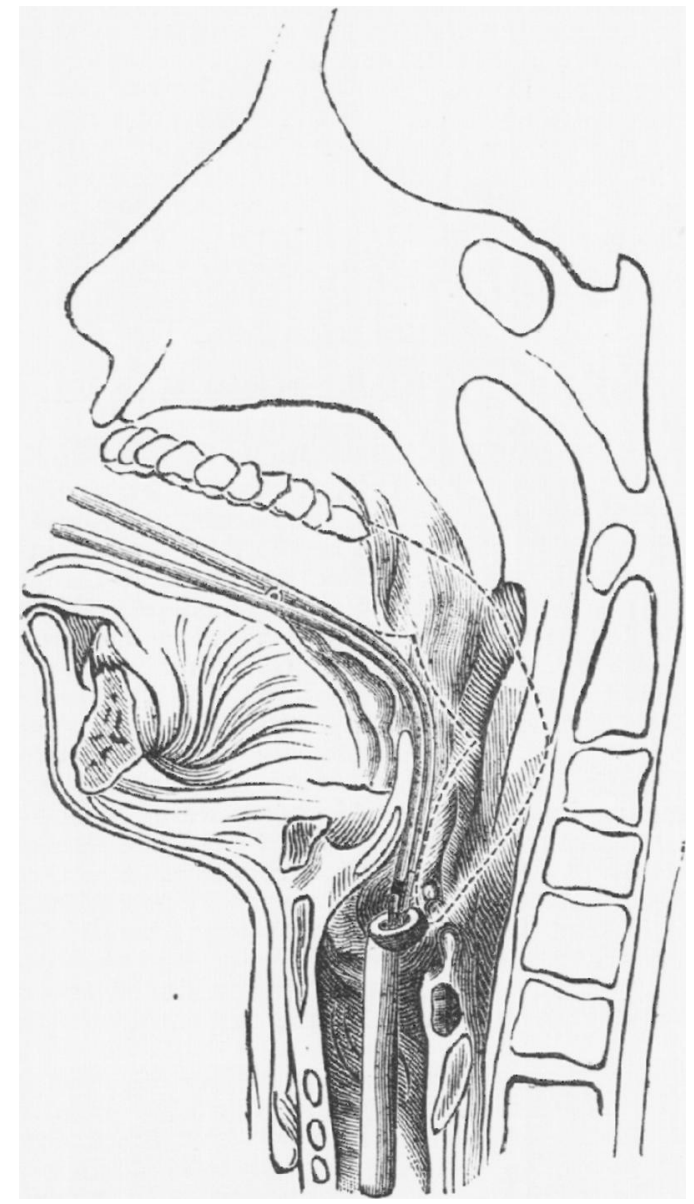

Fig. 10.

the last International Medical Congress, Dr. Max J. Stern reported a large number of cases of tracheotomy performed in various parts of the world, with recoveries amounting to 26 per cent. Let us compare the results with those of intubation.

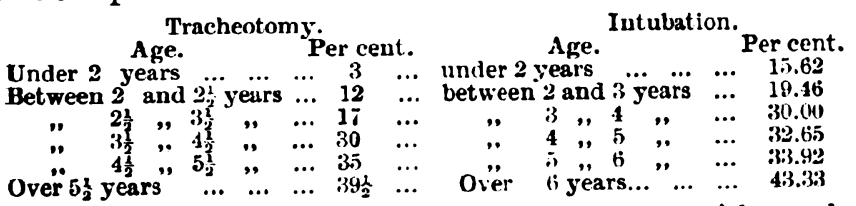

It will thus be seen that intubation holds its own with tracheotomy at all ages, and with the young and feeble children it offers advantages far superior to tracheotomy.

As all the objections to the operation have now been overcome, we may expect far better results in the future than in the past.

$1 \mathrm{My}$ attention was first called to the fact that children could swallow much better in this position by Dr. Frank Cary, of Chicago.

MR. H. Wickenar, of Rufford, Ormskirk, has received, for the thirteenth time in succession, the Government grant for vaccination.

\section{CLINICAL MEMORANDA.}

\section{A CASE IN WHICH DE.ATII OCCURRED DURING ADMINISTRATION OF CHLOROFORM.}

E. C., aged 40, a commercial traveller, on September 6 th was to be placed under the influence of an anæsthetic for the purpose of having some adhesions broken down in the knee-joint, the result of an old injury. The patient was a healthy-looking, welldeveloped man, apparently in every way sound, with the exception of pain, stiffness, and inability to fully use the left kneojoint. Chloroform was administered most carefully with a Junker's inhaler by Dr. S. Worthington, F.R.C.S.Eng., the acting assistant medical officer, a gentleman of much experience in the administration of anæsthetics. Patient took chloroform slowly and well, in quite a normal manner, slightly struggled, and went fully off in about five minutes. The inhaler was removed. I then commenced manipulations, forcibly flexing the knee; but almost directly he suddenly stopped breathing, and the face bocame cyanosed. The tongue was immediately drawn forward, windows opened, artificial respiration performed, hot flannels applied over the heart, and ether injected. Despite persevering and prolonged efforts, he never rallied; the heart stopped almost directly after the breathing, and, save for two or three gasps, showed no signs of life.

The necropsy revealed all the organs healthy except the heart, which was large and flabby, weighing 13 ounces. Its surface contained more fat than normal, although he was quite a spare man. The walls of both ventricles, especiully the right, were thin and pale, especially at the apex of the right rentricle, where the muscular tissue was thinned to less than one-thirty-second of an inch, and encroached upon by fat from the surface. The cavities were almost empty; the valves and coronary arteries healthy. The lungs were somewhat odematous, but their tissue normal. The left knee-joint had no signs of recent inflammation or active disease of any kind. There were several narrow bands of adhesion across the joint, especially in the situation of the ligamentum mucosum, bands from it to the inner side of patella and to the inner condyle, and others round the crucial ligaments. of fully flexing and extending the joint. With some force they were ruptured, and the knee could then be fully moved. Underneath the patella were two similar bands from the upper edge, reaching across the cartilage to the lower edge. During life, on
moving the patella from side to side, a feeling of crepitation was produced which gave the idea of some denudation of cartilage, but this was found not to be the case, and to be entirely due to these bands; in fact, there was no bare bone in the joint. There had been an old fracture just above the condyles, but the parts were in good position, and no bony prominences interfered with movement.

An inquest, was held on September 7 th, and the jury returned a verdict of "Accidental Deatl," adding that they were satisfied that every care and attention had been given to the case.

It has been my fate to be present at three deaths from this anxsthetic, given by experienced administrators, and in all these ansesthetic, given by felt convinced that it was respiration that first failed, and not the heart. I fancy there is still a widespread idea that in giving chloroform it is the pulse that should be watched, and in ether the respiration, or, in other words, that the former kills by the heart, the latter by the lungs. This error cannot be too seriously combatted, nor too energetically exposed. The instructions given by Sir Joseph Lister, in his excellent urticle on anasthetics, in the last edition of Holmes's System, is without doubt sound "During the inhalation the pulse should be entirely disregarded, but vigilant attention kept upon the respiration." $\mathrm{He}$ calls it 8 "pernicious error" the idea that chloroform kills by the heart. "In Fdinburgh, he goes on to say, the administrator who is only a In Fdinburgh, he goes on to say, the administrator who is only a be very interesting to know from him at this time, when so much attention is heing paid to the question, whether he has had any reason to alter his oft-cxpressed opinion as to chloroform being preferable to ether. When a leading surgeon in, perhaps, the standard work on surgery of the day, enunciates a doctrine which with him has stood the test of time, one would be very chary. without far more potent evidence than has been yet adduced, to declare him wrong.

The roluntary stoppage of respiration so common in the early 